\title{
Intellectual Management of Irrigation Systems in the Mountain-Irrigated Agriculture in Azerbaijan
}

\author{
Rans Aliev ZH* \\ Institute of Soil Science and Agrochemistry of NAS of Azerbaijan, Azerbaijan
}

Received: June 15, 2018; Published: June 26, 2018

*Corresponding author: Rans Aliev ZH, Institute of Soil Science and Agrochemistry of NAS of Azerbaijan, Baku, Azerbaijan

\begin{abstract}
This article examines the current state of soil and water resources, farmland t.ch.i Azerbaijan Republic, the problem of progressive water and wind soil degradation, the need for the organization of agriculture, taking into account the introduction of automated control systems for irrigation using water saving technology and hardware equipment in it, the study of the characteristics and analysis of experience implementing measures to stabilize ecological and drainage system of agriculture in conditions of insufficient moisture areas in the country , as well as basic aspects of development of environmental reclamation approach balanced, rational use of a particular system of crop rotation and crop taking into account the requirements of economic development and environmental management.
\end{abstract}

Keywords: Irrigation; Technology; Degradation; Automated Management of Low-Intensity Zones; Agriculture

\section{Introduction}

The main directions of economic and social development of the republic is the intensification of agricultural production. Irrigation is a powerful means of intensifying agricultural production in the conditions of its specialization. In areas of insufficient moisture (especially characteristic of mountainous areas), irrigation is one of the decisive factors in the cultivation of high and stable crop yields (Figure 1).

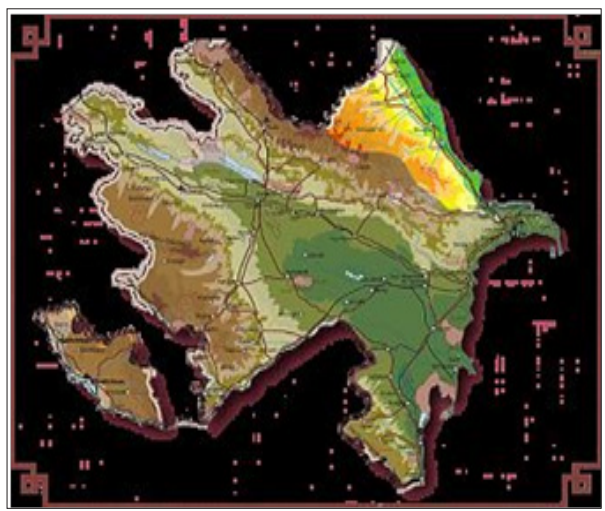

Figure 1.

Purpose of the Research: To this end, it is necessary to develop new technical solutions and introduce automated low-intensity irrigation systems for agricultural crops that meet the require ments of the environment and protect their habitat, which allows improving the ecological status of irrigated land, reducing water consumption per unit and increasing yields crops on the irrigated field.

\section{Methods of Research and Discussion}

Irrigated soils in Azerbaijan cover 1,45 thousand hectares. It is believed that the use of automation also applies to factors directly affecting the entrainment of crop yields and increasing the productivity of each hectare of arable land and agricultural land with minimal outlays of labour and resources. Automated irrigation increases the efficiency of all the intensification factors: chemicalization, complex mechanization, renewal grade, intensive technology, etc. It allows creating large zones of guaranteed crop production.

\section{Objects of Research}

The object of the study is to study and create methods of correct regulation of water consumption and plant nutrition by irrigation, depending on the weather conditions. To this end, we have developed and implemented in the design of systems for automated control of low-intensity irrigation systems based on a self-oscillating micro-oxidizer successfully passed the resource test, tested on selected soils under the orchard, in the Guba-Khachmassa zone on the Shahdag foothills located above the sea level at 600 meters with a slope of the terrain of 0.02 . (See Principal scheme of a pulse 
sprinkler system of self-oscillating action with automated control (Figure 2) So, for the operational control of weather conditions in the region, which are necessary for solving the planning and oper- ational management of irrigation of crop fields, metering sensors with transducers for telemetric counting of the main parameters are installed at the local hydrometeorological point:

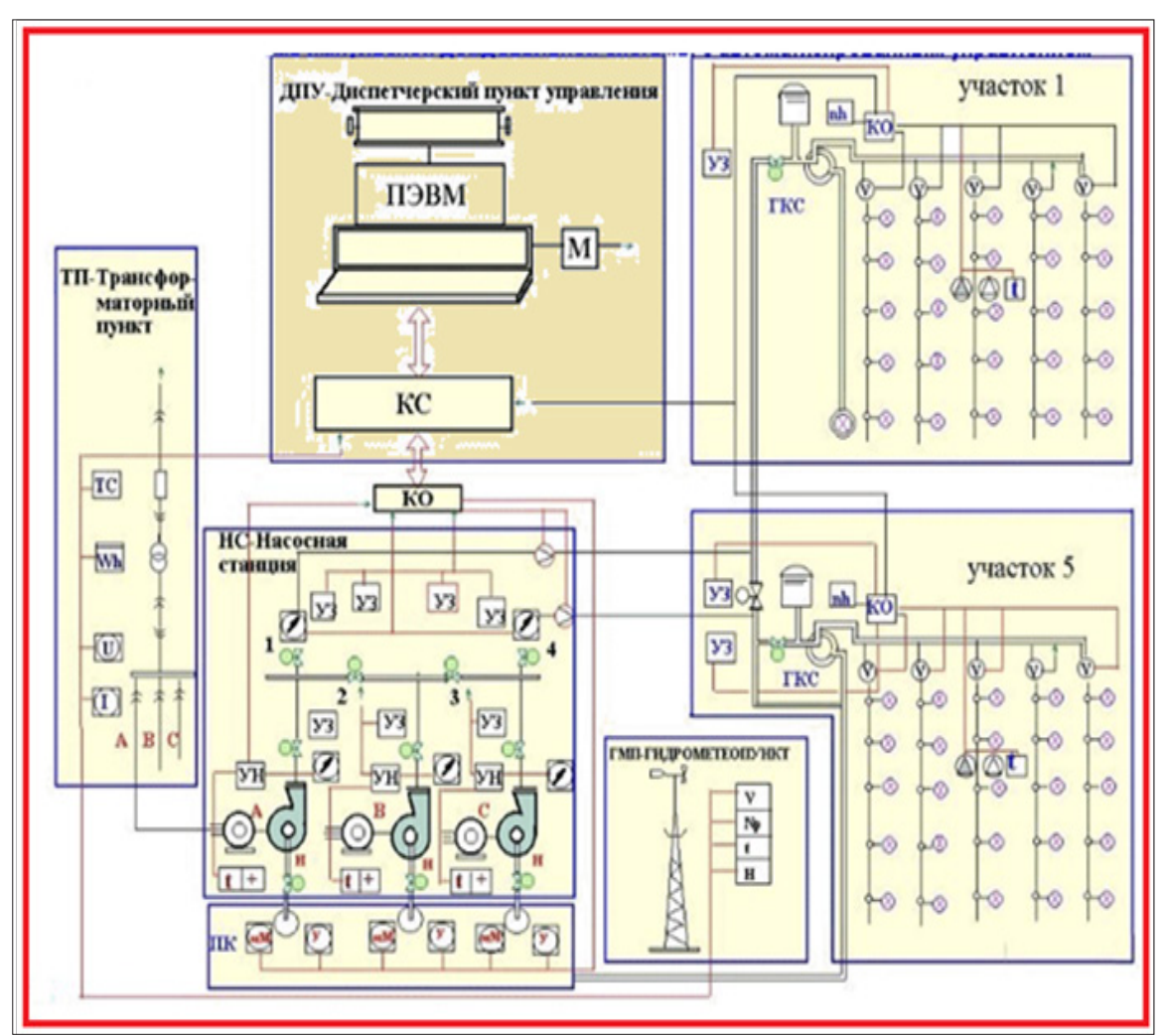

Figure 2: schematic diagram of a pulse sprinkler system of self-oscillating action with automated control Constructions and functional descriptions of the SMO AU.

a) Wind speed -V analog signal (TIT) with a period of recording the parameter values in a cycle of 30 minutes.

b) air temperature -tv, analogue signal (TIT) with a period of recording the parameter values in a cycle of $30 \mathrm{~min}$.

c) air humidity $-W_{B}$, analogue signal (ТИТ) with a period of recording the parameter values in a cycle of $30 \mathrm{~min}$.

The values of the parameters in the telemetry code are calculated by the intelligent object controller (KO) installed in the transformer station through the radio channel communicating with the transducer sensors. The QoS reckoned telemetry signals pass codes primary processing, averaging and written into RAM where they are stored until counting of communication controller (CC), installed indoors line control process (ASMO) -operator. To monitor and manage the power supply to ASMO facilities and to account for electricity consumption at the transformer station (TP) (see the structural and principle diagram of the APCS of irrigation), transducer sensors are installed:

a) measuring the voltage at the input in the TP-U (analog signal (TIT);

b) load measurement of consumers - I U (analog signal (TIT); c) Accounting for electricity consumption -Wh (discrete integrated signal-TII);

d) Control of the position of the switches (switching-off of electrical consumers) -SC (discrete signal TCC position).

The report parameter values in the telemetry code carried intelligent controller object (KO) on the local wired communication channels and after their initial treatment, and the averaging is written into memory .For control and process control intake, clarifiers (treatment plant) and the pump station (pressurization device water in pipelines) are installed sensors-converters specified in the structural-functional scheme:

a) turbidity of water in sedimentation tanks-M (analog signal TIT readable in a cycle of $30 \mathrm{~min}$ );

b) the water level in the sedimentation chambers- $\mathrm{H}$ (analog signal TIT, read in the cycle $30 \mathrm{~min}$ );

c) water pressure -P, installed on pumps, collection and distribution manifolds (analog signal TIT, read in a cycle of 30 minutes);

d) measurement of load of electric motors -I (analogue signal TIT, read in cycle $30 \mathrm{~min}$ ); 
e) positions of the gate valves-PZ (discrete TCC signal, read in cycle $1 \mathrm{~s}$ );

f) the positions of the power supply switches-VP (discrete TCC signal, read in cycle $1 \mathrm{~s}$ );

g) alarm-AS (discrete signal TCA, read in cycle $1 \mathrm{~s}$, priority);

h) measuring the flow rate of water supplied by pumps and in the distribution pipeline - $Q$ (integrated TII signal, processed in a cycle of 1 hour).

Monitoring of soil condition and management of the irrigation technological process is carried out according to individual irrigation fields based on measurements of agrophysical and technological parameters by transducer sensors:

a) soil moisture VLP- (analog signal TIT with recording in a cycle of $30 \mathrm{~min}$ );

b) evaporation of water from the soil surface -Isp - (analogue signal TIT with recording in a cycle of $30 \mathrm{~min}$ );

c) soil temperatures $-\mathrm{t}^{\circ}$ - (analogue signal TIT with recording in a cycle of $30 \mathrm{~min}$ );

d) water discharge for irrigation through the distribution pipelines of the section - $Q$ - (integrated signal with recording in a cycle of 30 minutes);

e) inclusion of GCS-discrete signal readable in a cycle of $30 \mathrm{~s}$;

f) the position of the switching valves - (discrete position signal TCC - reading cycle $30 \mathrm{~s}$ ).

The signal report in the telemetry code is carried out by the intelligent object field controller via radio communication channels and after their initial processing and averaging by the processor are written into the RAM

\section{Entering operational data into the computer and creat- ing a database (HBS)}

Recorded in the memory of controller's objects (KO) data are counted programs but by radio and wire liaison channels of communication controller (CC) which is connected to a computer control station (AP) (see. The concept of low-intensity irrigation system with automatic control), for a given regulation and are written into its operative memory in the structure of the telemetry file (see Information support). Computer on exchange programs reads the data from the RAM of the COP, transcodes them and writes the online database, from which displays them in real time on the display on the graphic presentation, and after linearization and averaging data on their codes of programs but written in the storage base, which structure are provided in the information support, and this forms the Data Bank of the complex for

a) With the help of Skype 3, users can talk over the phone and when using cameras to see each other, and with streaming video programs, look at the status of the site. When instrumental parameter measurements, it is necessary to take into account the scatter in the measured values. The value of the parameter, which can be taken as actual with a probability of 0.8 , is determined by the number of repetitions of measurements, determined by the formula:

$$
\left.n=0.88 x=1.64 * 0.001\left(S I G_{-} B\right) *((W(H B) / 10 * h) * * 2)\right)+2.27
$$

Where:

$\mathrm{n}=0.8$

(TP) -quantity, repetitions of measurements corresponding to a probability of 0.8 ;

m-0,8 (TP) -accuracy of measurements (mm)

Sb-standard measurement error,\%

b (HB) W (HB) - moisture dumps, mm

At humidity b (HB) in the control layer h (a), m.

\section{Measurement of initial (starting) soil moisture and cal- culation of initial moisture reserves W0 in soil}

a) General description of the Task:

The initial moisture reserves of $\mathrm{W} 0$ in the active soil layer are determined by the formula:

$$
d W H B=W(\operatorname{tau})-W(H B
$$

Where:

$\mathrm{h}$ (a) is the active layer of soil, $\mathrm{m}$ (it is assumed that the active layer of soil is divided into layers of $0.20-0.30 \mathrm{~m}$ ), $\gamma$ is the average soil density for the layer, $\mathrm{t} / \mathrm{m} 3$ is the entry in the program code-gamma_sp $\beta \tau$-soil moisture in the field area in $\%$ to the mass dry record in the code of the soil program at the considered moment - (Veta_tau). With the automatic determination of the initial moisture reserves in the soil, it is assumed that the value $\beta \tau$ (Вета_tau) is determined by the humidity meter installed in the balance area of the field according to n0.8 (TP) measurements (entry in program code $n_{-} 0.8 \mathrm{Ex}$ ). The measured parameter values are automatically written to the DataPar.dbf data bank by the N_code of the element to which the parameter belongs (see the special section "Information Support") [1,2]. To specify the calculation conditions, the values of the required conditionally variable variables are recorded in the task assignment (see ZADANIE_3 in information support). Having determined the value of the initial (initial) soil moisture, software determines the deficit of moisture reserves and the necessary irrigation rates. The results of the solution of the problem are recorded in the output document DOC_3 and are output as a diagram.

Description of the algorithm in accordance with the task of determining the soil moisture and moisture reserves in the field of irrigation (see the information section “REST_3)

Finding values from the database (from the Information Support section)

Parameter values are automatically read from the DataPar.dbf file by N_code of the element to which the parameter belongs; the value of the element's N_code is read from the ELEM file. Dbf by 
key: SL_SYST + SSYST + SL_MODYLE + SL_GROUP + SL_VID + SL TYPE. Formation of the key for searching N_code (see statement to the operator)

a) From the SL_SYST.dbf file, select the system to which the item parameter belongs.

b) From the file SL_SSYST.dbf select the subsystem.

c) From the file + SL_MODYLE .dbf -module.

d) From the file SL_GROUP.dbf -group, to which the element of the measured parameter belongs.

e) From the file SL_VID.dbf-the type of the element of the measured parameter.

f) From the file SL_ TYPE.dbf -type of the element of the measured parameter.

g) NAME-the element name is entered from the keyboard;

h) If there are several elements defined on the link (see ZADANIE_3, record

i) Then each of them is assigned a position number.

The element number is added to the name via the separator [_] - (NAME_1 $>$ ) /. On the generated coupler is TLS_X.dbfN_code. From DataPar.dbf to N_code + Zdate and the name of the parameter $<$ PARAM $>$ marked in ZADANIE_3 (+) is programmed its ZNACH value for each field.

A) The found values of the parameters-the humidity for a given date BETA_tau or the moisture reserves for a given date $\mathrm{W}$ (tau) for each section of the field are recorded in the output document DOC.3, see the layout of the output documents "Moisture reserve in irrigation fields". After determining the moisture content of BETA_tau or the moisture reserve in the soil W (tau), a moisture deficit or a moisture reserve in the soil is determined $[3,4]$.

Determination of the moisture deficit and moisture reserves in the soil in the field area.

a) If the humidity of BETA_tau is determined from ZADANIE_3 and its value is found from DataPar.dbf, then the moisture deficit relative to the moisture of the least water consumption BETA_ (HB) is: [2-8].

$$
d B E T A_{-} H B=B E T A_{-}(H B)-B E T A_{-} t a u
$$

Where,

BETA_(HB) -from SF_Plot. dbf and ConSoil. dbf; BETA_tau -from 5.4.3.

The obtained moisture deficit values are automatically recorded in the output document DOC.3

b) If the moisture reserve in the soil $\mathrm{W}$ (tau) is determined from ZADANIE_3 and its value is found from DataPar.dbf, the humidity moisture deficit at the lowest moisture capacity $\mathrm{dW}(\mathrm{HB})$ is equal to:

$$
d W(H B)=W(\operatorname{tau})-W(H B)
$$

Where,

$$
\begin{aligned}
& \text { W (HB) -from SF_Plot.dbf and } \\
& \text { ConSoil.dbf; W_tau -from 5.4.3 }
\end{aligned}
$$

After determining the data for each of the specified sections of the field is determined

a) average moisture content of BETA_AV and stocks

$$
\text { BETA_AV }=1 / n \Sigma\left(B E T A_{-} \text {tau }\right)
$$

Where,

$\mathrm{n}$ is the number of balanced sections participating in the calculation-

from ZADANIE_3, record 4;

(BETA_tau) $i$ is the moisture content of the soil with respect to dry soil from 5.4.1 for each plot.

b) if (W_tau) were determined, then the average value of the moisture reserve in the soil of the whole field

$$
\text { dBETA_AV }=1 / n * \Sigma\left(d B E T A_{-} \text {tau }\right) I
$$

c) mean value of moisture reserve deficit in the soil of the field:

$$
d W_{-} A V=1 / n \Sigma\left(d W_{-} A W\right) I
$$

The calculated values in $\S \S 5.4 .3$ (a), (b), (c), (d) are automatically written in a row $<$ in the mean over the field .......

d) The values of the parameters determined in columns 4,5 and 6 DOC. 3 are displayed with a bar graph "Moisture drop over the irrigation field"

e) After viewing the DOC.3 document, you will be prompted to $<$ Will solve the task for other farm fields on this date $>$. $<$ Yes $>$, $<$ No $>$. When you enter $<$ Yes $>$, the message $<$ Enter the field and farm name in ZADANIE_3> is displayed and displayed on the ZADANIE screen for data entry.

If the value of the parameters specified in ZADANIE_3 is absent in the database, then the message $<$ The value of the parameters specified in ZADANIE is absent in the database. Will you measure these parameters?. $<$ Yes $>$, <No $>$. If $<$ Yes $>$, then go to Section 4.4.1. If $<\mathrm{No}>$, then the task solution is finished and exit to the MENU. Before the start of the measurement, the number of measurements in each section is determined that ensures the probability of obtaining a value of at least 0.8 with the minimum labour costs for measuring n_0.8Ex:

$$
\left.\left.n_{-} 0.8 E x:=1,64 * 0.001\left(S I G_{-} B\right) *(W(H B) / 10 * h) * 2\right)\right)+2.27
$$

Where:

SIG_B-defined standard error in\%; BETA (HB) -from ZADANIE_3; -W (HB) -Pass moisture in soil, in mm with BETA (HB) moisture content of SF_Plot.dbf; -h-depth of soil layer ( $\mathrm{mm})$ in 
which the measurement is to be carried out. Execute n_0.8Ex measurements according to the specified parameter ZADANIE_3, line 2 in each section and write data in DataPar.dbf by N_code, Zdate, and Ztime. Calculate the average value from the completed measurements (make a selection from DataPar.dbf by N_code + Zdate. The average moisture reserve in the $\mathrm{W}_{-} \mathrm{AV}$ soil is:

$$
W_{-} A V=1 / n_{-} 0.8 E x * \Sigma\left(W_{-} 0.8 E x\right) i(\mathrm{~mm})
$$

Where,

W_0.8Ex is the moisture reserve value for each measurement selected in $\S 5.4 .6$ (If the soil moisture content BETA_0.8Ex was measured, then the average moisture value BETA_AV:

$$
B E T A_{-} A V=1 / n_{-} 0.8 E x * \Sigma\left(B E T A_{-} 0.8 E x\right) i(\%)
$$

Where

BETA_0,8 Ex -value of soil moisture for each measurement, calculate the values assigned:

a. W_AV: $=\mathrm{W}(\mathrm{tau})$

b. BETA_AV: = BETA_tau and write to the output document DOC. 3 as in 5.4 .1 and further as 5.4.2; 5.4.3.

The completed document DOC.3 is recorded in the folder for sending via the Internet. The program codes are listed in a separate application

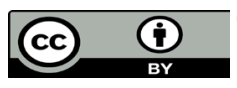

This work is licensed under Creative Commons Attribution 4.0 License

Submission Link: https://biomedres.us/submit-manuscript.php

\section{Conclusion}

Based on the results of the research, the possibilities of an operative solution of the complex problems of the operational determination of agro-meliorative parameters

\section{References}

1. Aliev BH, Aliev ZH (1999) and others Techniques and technology few intensive irrigations in condition of the mountain region Azerbaijan. Publishers “Elm”, Baku, pp. 220.

2. Aliev ZH (2007) The premises about the most important problem of the agriculture in the provision of water resources mountain and foothill regions Azerbaijan. J AAS, Baku, pp.179-182.

3. BH Aliev, Aliev ZH (2003) Irrigated agriculture in the mountain and foothill regions of Azerbaijan. Monograph Publishing House "Nurlan Zia EPG Ltd", Baku, pp. 330.

4. VF Nosenko (1981) Irrigation in the mountains. Publishing House "Kolos", Moscow, pp. 143.

5. Guseynov NM (1969) Ways to improve the efficiency of the use of irrigated land, improved technologies and methods for irrigation of agricultural crops in Azerbaijan. Report on the degree of competition, Baku pp. 214-230.

6. BH Aliev, Aliev ZH (2001) Zoning of territory of the Republic of Azerbaijan on selected advanced irrigation techniques. Monograph, Publishing house "Ziya”, Baku, pp. 297.

7. Aliev ZH (1999) In the mountains and foothill region of Azerbaijan. The works SRI “Erosions and Irrigations”, Baku, pp.125-129.

8. Mezhdunarodny Center (2002) C / X Research in the Dry in the Dry Areas (ICARDA) Irrigation regime and monitoring equipment. Pp. 128

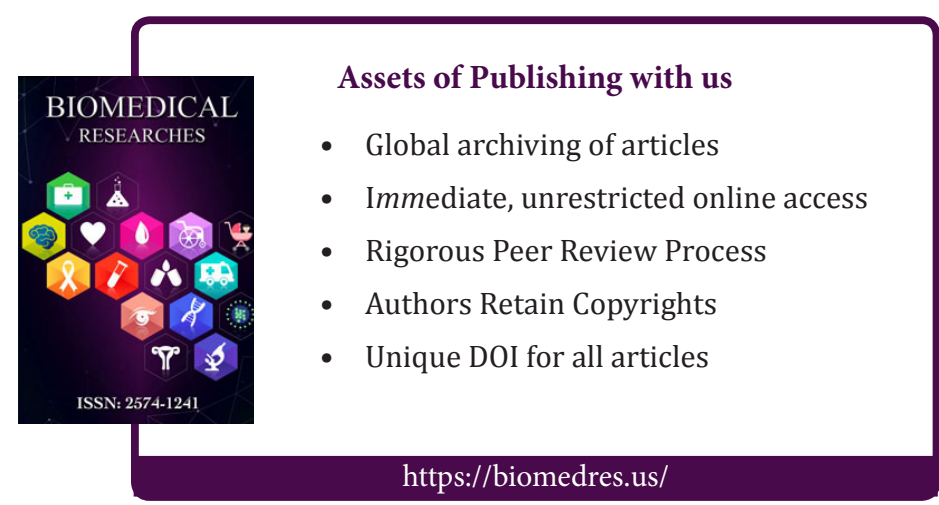

